\title{
Review Article \\ Integrated Stress Response as a Therapeutic Target for CNS Injuries
}

\author{
Lorenzo Romero-Ramírez, ${ }^{1}$ Manuel Nieto-Sampedro, ${ }^{1,2}$ and M. Asunción Barreda-Manso ${ }^{3}$ \\ ${ }^{1}$ Unidad de Neurología Experimental, Hospital Nacional de Parapléjicos (SESCAM), Finca la Peraleda s/n, 45071 Toledo, Spain \\ ${ }^{2}$ Departamento de Neurobiología Funcional y de Sistemas, Laboratorio de Plasticidad Neural, Instituto Cajal (CSIC), \\ Avenida Doctor Arce 37, 28002 Madrid, Spain \\ ${ }^{3}$ Laboratorio de Endocannabinoides y Neuroinflamación, School of Biosciences, Universidad Francisco de Vitoria, \\ 28223 Pozuelo de Alarcón, Madrid, Spain
}

Correspondence should be addressed to Lorenzo Romero-Ramírez; lromeroramirez@sescam.jccm.es

Received 5 January 2017; Revised 24 February 2017; Accepted 5 April 2017; Published 27 April 2017

Academic Editor: Alfredo Conti

Copyright (C) 2017 Lorenzo Romero-Ramírez et al. This is an open access article distributed under the Creative Commons Attribution License, which permits unrestricted use, distribution, and reproduction in any medium, provided the original work is properly cited.

\begin{abstract}
Central nervous system (CNS) injuries, caused by cerebrovascular pathologies or mechanical contusions (e.g., traumatic brain injury, TBI) comprise a diverse group of disorders that share the activation of the integrated stress response (ISR). This pathway is an innate protective mechanism, with encouraging potential as therapeutic target for CNS injury repair. In this review, we will focus on the progress in understanding the role of the ISR and we will discuss the effects of various small molecules that target the ISR on different animal models of CNS injury.
\end{abstract}

\section{Introduction}

CNS injuries are a diverse group of disorders that include spinal cord injury (SCI), traumatic brain injury (TBI), and stroke. Although different in etiology, CNS injuries trigger shared processes such as disruption of the blood-brain barrier (BBB) $[1,2]$ or the blood-spinal cord barrier (BSCB) [3] that facilitate the extravasation of blood substances and cells into the CNS parenchyma and vice versa, excitotoxicity [4-6], and hypoxia/ischemia $[5,7]$, increase the inflammatory response activated after injury $[5,7,8]$, and spread the initial cell death due to the injury to other CNS areas, with added detrimental effects.

This acute neuroinflammatory response causes the activation of glial cells (mainly astrocytes and microglia) that counterbalance the changes in tissue homeostasis $[9,10]$. Glial cells show enhanced migration into the injured site $[11,12]$ and release inflammatory mediators including proand anti-inflammatory cytokines and chemokines $[9,10]$. The proinflammatory mediators induce the activation and recruitment of leukocytes to the inflammation site in the CNS parenchyma $[10,13]$. Activated microglia (CNS resident macrophages [14]), as well as infiltrating neutrophils [15] and monocytes [16], phagocyte debris from damaged tissue and dead cells. Activated astrocytes and mesenchymal cells (meningeal fibroblasts [17], perivascular fibroblasts [18], and pericytes [19]) migrate to the injury site and attempt to restore the disrupted $\mathrm{BBB}$ or $\mathrm{BSCB}$, secreting extracellular matrix proteins that induce a new glia limitans, called glial scar [17, 20]. Both phagocytosis of dead cells and glial scar formation attempt to reduce inflammation and restore tissue homeostasis $[21,22]$. However, both processes might have detrimental effects. Activated microglia/macrophages may phagocyte living cells increasing tissue loss [23] and the glial scar is one of the main obstacles to axonal regeneration after injury [24]. If these processes cannot restore homeostasis, the inflammatory response is maintained long after injury. This state of chronic neuroinflammation increases further the loss of white and grey matter that characterizes many CNS pathologies $[25,26]$.

\section{Integrated Stress Response in CNS Injury}

CNS injury can cause oxygen-glucose deprivation, amino acid deprivation, glutamate excitotoxicity, oxidative stress, 


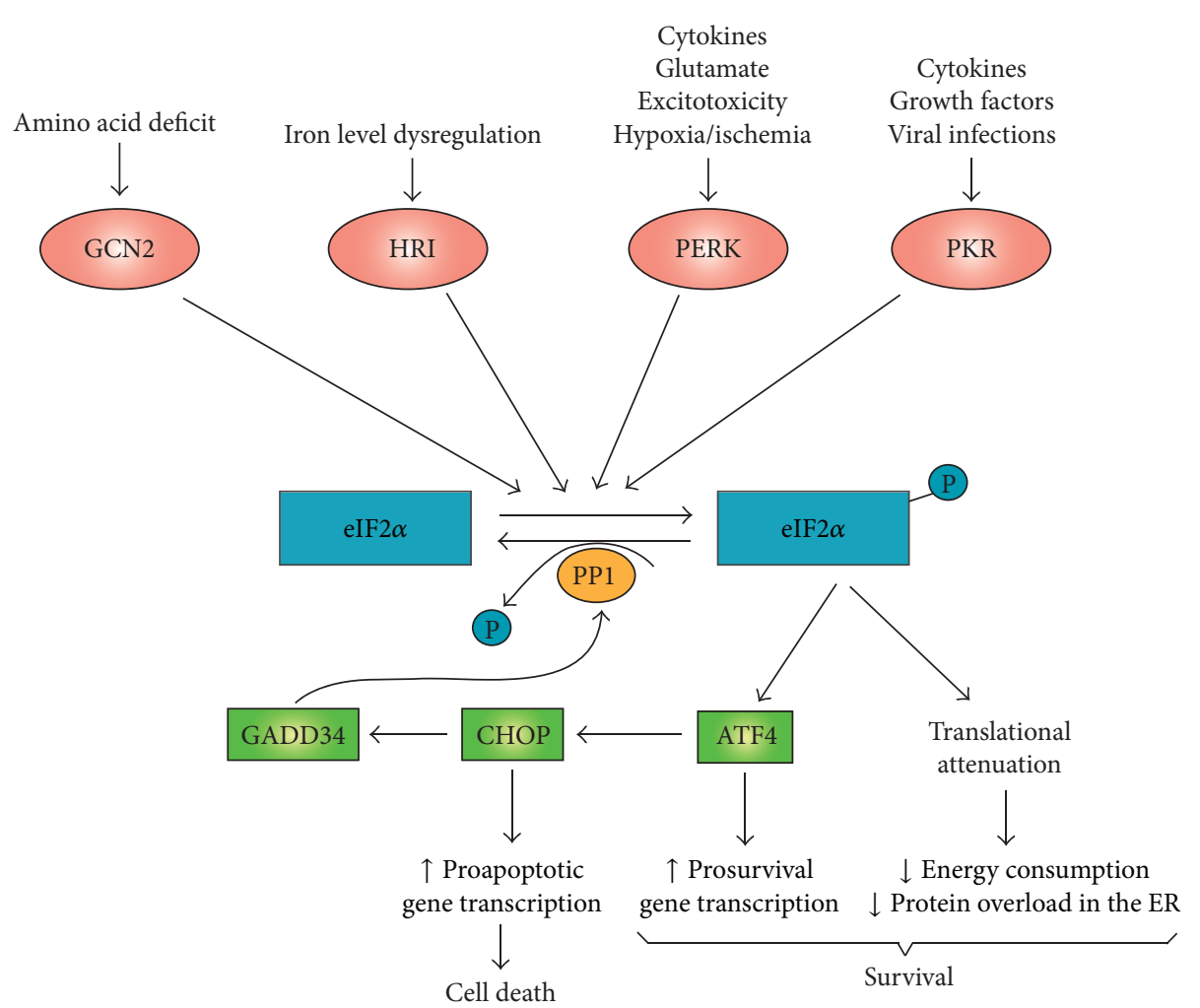

FIGURE 1: The integrated stress response is sensitive to numerous stimuli activated after CNS injury. A diverse group of kinases such as GCN2, HRI, PERK, and PKR induce the phosphorylation of eIF2 $\alpha$ in response to various stimuli resulting in translational attenuation to overcome the accumulation of misfolded or unfolded proteins in the ER and retrieve proteostasis. Phosphorylated eIF $2 \alpha$ (eIF $2 \alpha$-P) enhances the translation of the transcription factor ATF4 that induces the transcription of prosurvival genes as well as the transcription factor CHOP. Both ATF4 and $\mathrm{CHOP}$ cause upregulation of GADD34 expression, which forms a complex with PP1, inducing the dephosphorylation of eIF2 $\alpha$-P and hence retrieving translation. When protein homeostasis is not restored (indicating cellular damage), CHOP increases the transcription of proapoptotic genes, inducing cell death. ATF4, activating transcription factor 4; CHOP, C/EBP homolog protein; eIF $2 \alpha$, eukaryotic translation initiation factor $2 \alpha$; GADD34, growth arrest and DNA-damage inducible 34; GCN2, general control nonderepressible 2; HRI, haem-regulated inhibitor kinase; P, inorganic phosphate; PERK, protein kinase RNA-like endoplasmic reticulum kinase; PKR, double-stranded RNA-activated protein kinase; PP1, protein phosphatase 1.

and the release of cytokines. These may affect protein synthesis at the endoplasmic reticulum (ER), inducing the accumulation of misfolded or unfolded proteins therein [27-30] (Figure 1). The integrated stress response (ISR) is activated as a cytoprotective mechanism [31], to maintain cellular protein-folding homeostasis (also known as proteostasis) [32]. A diverse group of kinases (Figure 1) act as sensors for different stressors activating the ISR, through the phosphorylation of the alpha subunit of the eukaryotic translation initiation factor 2 (eIF $2 \alpha$ to eIF $2 \alpha$-P) on Serine 51 [32]. Phosphorylated eIF $2 \alpha$ binds to eukaryotic translation initiation factor $2 \mathrm{~B}$ (eIF2B). This inhibits its activity and attenuates protein translation while inducing the translation of activating transcription factor 4 (ATF4, also known as CREB2) and other selected genes [30]. ATF4 upregulates the expression of chaperones (e.g., Bip, also known as GRP78 $[33,34])$ that help to reduce protein accumulation in the ER. It also promotes the expression of prosurvival factors involved in amino acid metabolism and oxidative stress resistance [30, 35]. Moreover, ATF4 increases the expression of transcription factor $\mathrm{CHOP}(\mathrm{C} / \mathrm{EBP}$ homologous protein, also known as DDIT3, DNA-damage-inducible transcript 3). Both ATF4 and CHOP upregulate the expression of GADD34 (growth arrest and DNA-damage inducible 34; also known as protein phosphatase 1 regulatory subunit 15A or PPP1R15A). GADD34 is a regulatory cofactor of the catalytic subunit of protein phosphatase 1 (PP1) that directs the dephosphorylation of $\mathrm{eIF} 2 \alpha$ restoring protein synthesis [36]. Should the restoration of proteostasis fail, the transcription factor $\mathrm{CHOP}$ would cause an increase in the expression of genes involved in apoptosis, executing the damaged cell [37].

In addition to the stress-inducible GADD34-PP1 complex, CReP (constitutive repressor of eIF $2 \alpha$ phosphorylation, also known as PPP1R15B) forms a complex with PP1 that constitutively dephosphorylates eIF $2 \alpha$ [38].

\section{CNS Injury Therapeutics Based on the Integrated Stress Response}

CNS injury causes the loss of white and grey matter with detrimental effects $[25,26]$. After the initial cell death and 


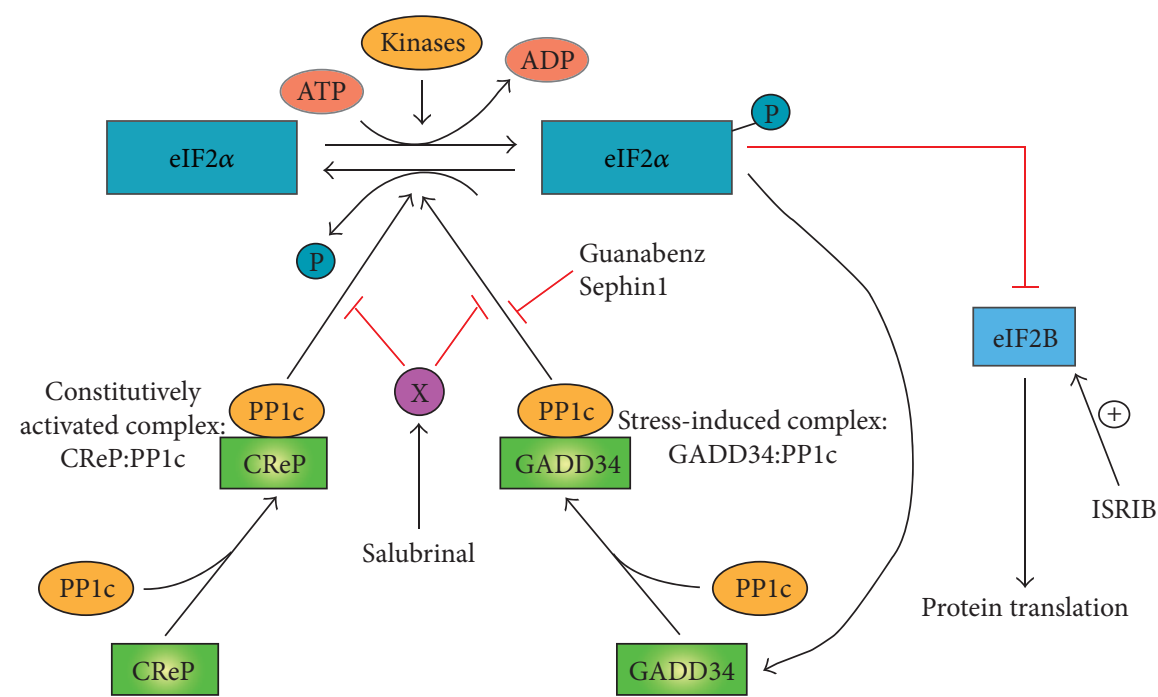

FIGURE 2: Pharmacological regulation of the integrated stress response (ISR). The translation initiation factor eIF $2 \alpha$ is phosphorylated (eIF2 $\alpha$-P) by a diverse group of kinases. Phosphorylated eIF2 $\alpha$ represses eIF2B inducing translation attenuation as well as activation of a pathway that induces GADD34 forming a complex with PP1c (GADD34:PP1c). This stress-activated complex induces the desphosphorylation of eIF2 $\alpha$-P to restore proteostasis. A constitutively activated complex (CReP:PP1c) dephosphorylates eIF2 $\alpha$-P under basal conditions. Salubrinal inhibits indirectly the activity of both GADD34:PP1c and CReP:PP1c complexes through an unknown target (X). However, Guanabenz and Sephin1 only inhibit the activity of GADD34:PP1c complex. ISRIB overcomes the attenuation of translation induced by eIF2 $\alpha$-P, activating eIF2B downstream of eIF $2 \alpha$. ADP, adenosine diphosphate; ATP, adenosine triphosphate; CReP, constitutive repressor of eIF $2 \alpha$ phosphorylation; eIF $2 \alpha$, eukaryotic translation initiation factor $2 \alpha$; eIF2 $\alpha$ B, eukaryotic translation initiation factor 2B; GADD34, growth arrest and DNAdamage inducible 34; ISRIB, integrated stress response inhibitor; P, inorganic phosphate; PP1c, protein phosphatase 1 catalytic subunit.

tissue destruction caused by the injury, numerous mechanisms are activated spreading both tissue damage and cell death (like excitotoxicity [4-6], hypoxia/ischemia [5, 7, 8], and so forth). CNS injuries enhance the ISR pathway as a cytoprotective mechanism [27, 39], suggesting that the ISR might be a therapeutic target for CNS injuries. Several small molecules, such as salubrinal [40], guanabenz [41], and Sephin1 [42], that enhance ISR have shown cytoprotective effects.

3.1. Salubrinal. Salubrinal is a small molecule discovered in a high-throughput screening of compounds with cytoprotective effect on ER stress-induced cell death [40]. Although the target for salubrinal is unknown, it maintains eIF $2 \alpha$ highly phosphorylated, reducing protein synthesis at the ER [40]. Salubrinal inhibits the activity of both CReP-PP1 constitutive complex and GADD34-PP1 stress-inducible complex (Figure 2).

Salubrinal has neuroprotective effects in animal models of CNS injury, such as a rat brain excitotoxicity [43], cerebral ischemia/reperfusion $[44,45]$, and chronic intermittent hypoxia [46]. It is neuroprotective also in mouse models of sleep apnea [47], traumatic brain injury [48, 49], and cortical stab injury [50]. Moreover, salubrinal protects oligodendrocytes, reducing demyelination and improving functional recovery after spinal cord injury [51]. The prosurvival effects of salubrinal after CNS injury are mediated by decreasing the ER stress response [43, 45, 48-50]. Limiting energy consumption is achieved under pathological conditions by diminishing ER protein overload [52].
Recent evidence suggests that salubrinal treatment may trigger additional cytoprotective pathways by upregulating the expression of platelet-derived growth factor subunit $\mathrm{B}$ (PDGF-B) [53-56] in neurons close to the injury [50]. After a cortical stab injury, salubrinal also helps in restoring the integrity of the blood-brain barrier (BBB) by inducing an increase of fibronectin expression and a reduction of the activation of microglia/macrophages [50]. A rapid restoration of the $\mathrm{BBB}$ integrity following injury is essential to restore homeostasis [57]. Should this process be delayed or impeded, blood substances and leukocytes would continue diffusing into the CNS, triggering an additional inflammatory process. This would extend the initial injury, strengthening the socalled secondary neuronal loss, with increased detrimental effects [58]. PDGF-B is a mitogen for pericytes and mesenchymal cells [59], inducing both proliferation and production of fibronectin [60]. The release of PDGF-B in the proximity of the lesion site might help to close the injury, accelerating $\mathrm{BBB}$ integrity restoration [50]. Moreover, in a rat model of global cerebral ischemia, salubrinal reduced the levels of matrix metalloprotease 9 (MMP-9), as well as of the injury-induced cell adhesion molecules ICAM-1 and VCAM1 [46]. MMP-9 is a typical marker of BBB impairment $[61,62]$ and both ICAM-1 and VCAM-1 are involved in leukocyte migration into the injured CNS [63]. In conclusion, these results support the restorative effect of salubrinal treatment on BBB integrity after injury $[50,64]$. The reduction of both microglia activation and blood monocyte infiltration into the injury site may diminish inflammation, reducing neuronal death and tissue loss after injury $[50,64]$. 
Salubrinal may show additional neuroprotective and antiinflammatory effects by inhibiting the transcription factor $\mathrm{NF} \kappa \mathrm{B}$ pathway $[65,66]$. Indeed, salubrinal treatment reduced both neuronal cell death and microglia activation by $\beta$ amyloid $(\mathrm{A} \beta)$ [65] inhibiting the $\mathrm{NF} \kappa \mathrm{B}$ pathway. The authors propose that these effects are mediated by the inhibition of IkB kinase (IKK) activation, consequently reducing the degradation of the $\mathrm{NF} \kappa \mathrm{B}$ repressor IkB [65]. Another article reported that both salubrinal and guanabenz selectively reduce TNF $\alpha$ but not IL-1 $\beta$-induced activation of NFK B [66]. This work concluded that the effect occurred upstream of transforming growth factor/beta-activated kinase 1 (TAK1) and was independent of $\operatorname{eIF} 2 \alpha$ [66]. These results suggest that both salubrinal and guanabenz may regulate also the phosphorylation of other targets [67].

Following severe CNS injuries, glial cells (mainly astrocytes) and mesenchymal cells (fibroblasts and pericytes) attempt to restore the disrupted $\mathrm{BBB}$, by secreting extracellular matrix proteins and forming a new glia limitans, called the glial scar [17]. Although glial scar formation has some beneficial effects [68], it is also one of the main obstacles to axonal regeneration after injury [24]. The major axon regenerative growth inhibitors in the glial scar are the chondroitin sulfate proteoglycans (CSPGs) [69]. The neuritogenic effects shown by salubrinal in vitro are due to the inhibition of the expression in glial cells of CSPGs and other profibrotic proteins, such as CTGF [70]. In addition to the effect on protein translation, salubrinal reduced the mRNAs for CSPGs and CTGF [52]. These processes may work together to reduce protein overload in the ER, speed up proteostasis, and increase cell survival after CNS injury.

These results suggest that salubrinal could be a good candidate for pharmacological therapy of CNS injuries. Detrimental effects of salubrinal treatment have been reported in pancreatic beta cells exposed to fatty acids [71] and in the neuroprotection induced by preconditioning, in a rodent model of permanent ischemia [72]. Since the mechanism of action of salubrinal is unknown, these adverse effects might be due to inhibition by salubrinal treatment of both constitutive and stress-induced phosphorylation of eIF $2 \alpha$ [73], or an off-target effect.

3.2. Guanabenz and Sephin1. Guanabenz is an agonist of the $\alpha 2$-adrenergic receptor and it is a prescription drug to treat hypertension [74]. In addition, guanabenz selectively inhibits stress-induced dephosphorylation of eIF $2 \alpha$ by the GADD34:PP1 complex, without affecting the activity of the constitutively activated CReP:PP1 complex (Figure 2) [41]. Guanabenz showed beneficial effects in a rodent model of multiple sclerosis, suggesting that the inhibition of GADD34:PP1 complex alone was enough to improve mouse recovery [75]. In particular, guanabenz was cytoprotective for oligodendrocytes and reduced demyelination [75]. These positive results have led to a phase I clinical trial to determine the safe dose of guanabenz for multiple sclerosis patients [73].

In contrast to multiple sclerosis, guanabenz treatment in rodent models of CNS injuries showed contradictory effects. Thus, it was cytoprotective for oligodendrocyte precursor cells (OPC) in vitro, but it did not enhance functional recovery in a mouse model of SCI [76]. In a rat model of TBI, guanabenz was neuroprotective, reduced cortical contusion, and decreased hipocampal cell damage, attenuating motor, learning, and memory deficits after TBI [77]. However, the dose of guanabenz in TBI experiments was five times higher $(5 \mathrm{mg} / \mathrm{Kg})$ than in SCI experiments $(1 \mathrm{mg} / \mathrm{Kg})$. In mice, a dose of guanabenz in that range $(1-5 \mathrm{mg} / \mathrm{Kg})$ has side effects manifested by a dose-dependent decrease in rotarod performances [42]. These side effects may be due to the effect of the drug on adrenergic receptors, lowering mice blood pressure. TBI mice treated with the FDA-approved dose range $(0.5 \mathrm{mg} / \mathrm{Kg})$ had beneficial effects, but not all the benefits observed with the higher dose [77]. Guanabenz is used to lower blood pressure in patients with hypertension. A high dose of guanabenz has side effects, including drowsiness and coma [78]. These results hamper the possible use of guanabenz for treatment of CNS injuries.

Sephin1 is a guanabenz derivative with selective inhibitory effect on stress-induced dephosphorylation of eIF2 $\alpha$ by the GADD34:PP1 complex (Figure 2), without $\alpha 2$-adrenergic activity [42]. Sephinl showed beneficial effects on animal models of two protein-misfolding diseases, Charcot-Marie-tooth 1B (CMT1B) and Amyotrophic lateral sclerosis (ALS), without any side effect in chronic treatments [42]. In particular, Sephin1 treatment $(1-5 \mathrm{mg} / \mathrm{Kg})$ did not decrease mice performance in rotarod, or in the Morris water maze, that tests spatial learning [42]. In fact, mice treated with Sephinl prevented motor deficits in untreated mice of $\mathrm{MPZ}^{\text {mutant }}$ (a mouse model of CMT1B) and SOD1 ${ }^{\text {mutant }}$ (a mouse model of ALS).

It is unknown whether Sephinl treatment has beneficial effects on CNS injuries. The desirable properties of Sephin1, such as specificity for stress-induced complex and the reduced $\alpha 2$-adrenergic activity, deserve a study to determine its therapeutic potential for CNS injuries.

\section{Conclusions}

The integrated stress response (ISR) is a cytoprotective mechanism induced in CNS injuries. The enhancement of ISR pathway by the small molecule salubrinal is neuroprotective and neuritogenic and helps to restore BBB integrity after injury. A new generation of small molecules that enhances the ISR pathway, such as Sephin1, is currently under investigation to determine their potential for the treatment of CNS injuries. Preliminary results indicate that the enhancement of the ISR pathway is a promising therapeutic target for CNS injuries.

\section{Conflicts of Interest}

The authors declare that there are no conflicts of interest regarding the publication of this paper.

\section{References}

[1] A. Chodobski, B. J. Zink, and J. Szmydynger-Chodobska, "Blood-brain barrier pathophysiology in traumatic brain injury," Translational Stroke Research, vol. 2, no. 4, pp. 492-516, 2011. 
[2] T. Kahles, P. Luedike, M. Endres et al., "NADPH oxidase plays a central role in blood-brain barrier damage in experimental stroke," Stroke, vol. 38, no. 11, pp. 3000-3006, 2007.

[3] J. T. Maikos and D. I. Shreiber, "Immediate damage to the blood-spinal cord barrier due to mechanical trauma," Journal of Neurotrauma, vol. 24, no. 3, pp. 492-507, 2007.

[4] T. W. Lai, S. Zhang, and Y. T. Wang, "Excitotoxicity and stroke: identifying novel targets for neuroprotection," Progress in Neurobiology, vol. 115, pp. 157-188, 2014.

[5] C. Werner and K. Engelhard, "Pathophysiology of traumatic brain injury," British Journal of Anaesthesia, vol. 99, no. 1, pp. 4-9, 2007.

[6] E. Park, A. A. Velumian, and M. G. Fehlings, "The role of excitotoxicity in secondary mechanisms of spinal cord injury: a review with an emphasis on the implications for white matter degeneration," Journal of Neurotrauma, vol. 21, no. 6, pp. 754774, 2004.

[7] A. E. Mautes, M. R. Weinzierl, F. Donovan, and L. J. Noble, "Vascular events after spinal cord injury: contribution to secondary pathogenesis," Physical Therapy, vol. 80, no. 7, pp. 673-687, 2000.

[8] R. Jin, G. Yang, and G. Li, "Inflammatory mechanisms in ischemic stroke: role of inflammatory cells," Journal of Leukocyte Biology, vol. 87, no. 5, pp. 779-789, 2010.

[9] Y. Dong and E. N. Benveniste, "Immune function of astrocytes," Glia, vol. 36, no. 2, pp. 180-190, 2001.

[10] F. Aloisi, "Immune function of microglia," Glia, vol. 36, no. 2, pp. 165-179, 2001.

[11] S. Bardehle, M. Krüger, F. Buggenthin et al., "Live imaging of astrocyte responses to acute injury reveals selective juxtavascular proliferation," Nature Neuroscience, vol. 16, no. 5, pp. 580586, 2013.

[12] D. Davalos, J. Grutzendler, G. Yang et al., "ATP mediates rapid microglial response to local brain injury in vivo," Nature Neuroscience, vol. 8, no. 6, pp. 752-758, 2005.

[13] S.-M. Lucas, N. J. Rothwell, and R. M. Gibson, "The role of inflammation in CNS injury and disease," The British Journal of Pharmacology, vol. 147, supplement 1, pp. S232-S240, 2006.

[14] H. Neumann, M. R. Kotter, and R. J. M. Franklin, "Debris clearance by microglia: an essential link between degeneration and regeneration," Brain, vol. 132, no. 2, pp. 288-295, 2009.

[15] E. Kenne, A. Erlandsson, L. Lindbom, L. Hillered, and F. Clausen, "Neutrophil depletion reduces edema formation and tissue loss following traumatic brain injury in mice," Journal of Neuroinflammation, vol. 9, article 17, 2012.

[16] R. M. Ritzel, A. R. Patel, J. M. Grenier et al., "Functional differences between microglia and monocytes after ischemic stroke," Journal of Neuroinflammation, vol. 12, no. 1 article 106, 2015.

[17] M. Berry, W. L. Maxwell, A. Logan et al., "Deposition of Scar Tissue in the Central Nervous System," in Trauma and Regeneration, vol. 32 of Acta Neurochirurgica Supplementum, pp. 31-53, Springer, Vienna, Austria, 1983.

[18] C. Soderblom, X. Luo, E. Blumenthal et al., "Perivascular fibroblasts form the fibrotic scar after contusive spinal cord injury," Journal of Neuroscience, vol. 33, no. 34, pp. 13882-13887, 2013.

[19] C. Göritz, D. O. Dias, N. Tomilin, M. Barbacid, O. Shupliakov, and J. Frisén, "A pericyte origin of spinal cord scar tissue," Science, vol. 333, no. 6039, pp. 238-242, 2011.

[20] J. W. Fawcett and R. A. Asher, "The glial scar and central nervous system repair," Brain Research Bulletin, vol. 49, no. 6, pp. 377391, 1999.
[21] T. Tanaka, M. Ueno, and T. Yamashita, "Engulfment of axon debris by microglia requires p38 MAPK activity," Journal of Biological Chemistry, vol. 284, no. 32, pp. 21626-21636, 2009.

[22] R. Shechter, C. Raposo, A. London, I. Sagi, and M. Schwartz, "The glial scar-monocyte interplay: a pivotal resolution phase in spinal cord repair," PLoS ONE, vol. 6, no. 12, Article ID e27969, 2011.

[23] G. C. Brown and J. J. Neher, "Microglial phagocytosis of live neurons," Nature Reviews Neuroscience, vol. 15, no. 4, pp. 209216, 2014.

[24] P. Bovolenta, F. Wandosell, and M. Nieto-Sampedro, "CNS glial scar tissue: a source of molecules which inhibit central neurite outgrowth," Progress in Brain Research, vol. 94, pp. 367-379, 1992.

[25] P. G. Popovich, Z. Guan, V. McGaughy, L. Fisher, W. F. Hickey, and D. M. Basso, "The neuropathological and behavioral consequences of intraspinal microglial/macrophage activation," Journal of Neuropathology \& Experimental Neurology, vol. 61, no. 7, pp. 623-633, 2002.

[26] O. N. Hausmann, "Post-traumatic inflammation following spinal cord injury," Spinal Cord, vol. 41, no. 7, pp. 369-378, 2003.

[27] C. Penas, M.-S. Guzmán, E. Verdú, J. Forés, X. Navarro, and C. Casas, "Spinal cord injury induces endoplasmic reticulum stress with different cell-type dependent response," Journal of Neurochemistry, vol. 102, no. 4, pp. 1242-1255, 2007.

[28] M. Shibata, H. Hattori, T. Sasaki, J. Gotoh, J. Hamada, and Y. Fukuuchi, "Activation of caspase-12 by endoplasmic reticulum stress induced by transient middle cerebral artery occlusion in mice," Neuroscience, vol. 118, no. 2, pp. 491-499, 2003.

[29] S. F. Larner, R. L. Hayes, D. M. McKinsey, B. R. Pike, and K. K. W. Wang, "Increased expression and processing of caspase-12 after traumatic brain injury in rats," Journal of Neurochemistry, vol. 88, no. 1, pp. 78-90, 2004.

[30] H. P. Harding, Y. Zhang, H. Zeng et al., "An integrated stress response regulates amino acid metabolism and resistance to oxidative stress," Molecular Cell, vol. 11, no. 3, pp. 619-633, 2003.

[31] W. E. Balch, R. I. Morimoto, A. Dillin, and J. W. Kelly, "Adapting proteostasis for disease intervention," Science, vol. 319, no. 5865, pp. 916-919, 2008.

[32] K. Pakos-Zebrucka, I. Koryga, K. Mnich, M. Ljujic, A. Samali, and A. M. Gorman, "The integrated stress response," EMBO Reports, vol. 17, no. 10, pp. 1374-1395, 2016.

[33] S. Luo, P. Baumeister, S. Yang, S. F. Abcouwer, and A. S. Lee, "Induction of Grp78/BiP by translational block: activation of the Grp78 promoter by ATF4 through an upstream ATF/CRE site independent of the endoplasmic reticulum stress elements," Journal of Biological Chemistry, vol. 278, no. 39, pp. 3737537385, 2003.

[34] A. S. Lee, "Glucose-regulated proteins in cancer: molecular mechanisms and therapeutic potential," Nature Reviews Cancer, vol. 14, no. 4, pp. 263-276, 2014.

[35] H. P. Harding, I. Novoa, Y. Zhang et al., "Regulated translation initiation controls stress-induced gene expression in mammalian cells," Molecular Cell, vol. 6, no. 5, pp. 1099-1108, 2000.

[36] M. H. Brush, D. C. Weiser, and S. Shenolikar, "Growth arrest and DNA damage-inducible protein GADD34 targets protein phosphatase $1 \alpha$ to the endoplasmic reticulum and promotes dephosphorylation of the $\alpha$ subunit of eukaryotic translation initiation factor 2," Molecular and Cellular Biology, vol. 23, no. 4, pp. 1292-1303, 2003. 
[37] D. Ron and P. Walter, "Signal integration in the endoplasmic reticulum unfolded protein response," Nature Reviews Molecular Cell Biology, vol. 8, no. 7, pp. 519-529, 2007.

[38] C. Jousse, S. Oyadomari, I. Novoa et al., "Inhibition of a constitutive translation initiation factor $2 \alpha$ phosphatase, CReP, promotes survival of stressed cells," Journal of Cell Biology, vol. 163, no. 4, pp. 767-775, 2003.

[39] R. Kumar, S. Azam, J. M. Sullivan et al., "Brain ischemia and reperfusion activates the eukaryotic initiation factor 2alpha kinase, PERK," Journal of Neurochemistry, vol. 77, no. 5, pp. 1418-1421, 2001.

[40] M. Boyce, B. F. Py, A. G. Ryazanov et al., "A pharmacoproteomic approach implicates eukaryotic elongation factor 2 kinase in ER stress-induced cell death," Cell Death and Differentiation, vol. 15, no. 3, pp. 589-599, 2008.

[41] P. Tsaytler, H. P. Harding, D. Ron, and A. Bertolotti, "Selective inhibition of a regulatory subunit of protein phosphatase 1 restores proteostasis," Science, vol. 332, no. 6025, pp. 91-94, 2011.

[42] I. Das, A. Krzyzosiak, K. Schneider et al., "Preventing proteostasis diseases by selective inhibition of a phosphatase regulatory subunit," Science, vol. 348, no. 6231, pp. 239-242, 2015.

[43] A.-L. Sokka, N. Putkonen, G. Mudo et al., "Endoplasmic reticulum stress inhibition protects against excitotoxic neuronal injury in the rat brain," The Journal of Neuroscience, vol. 27, no. 4, pp. 901-908, 2007.

[44] V. P. Nakka, A. Gusain, and R. Raghubir, "Endoplasmic reticulum stress plays critical role in brain damage after cerebral ischemia/reperfusion in rats," Neurotoxicity Research, vol. 17, no. 2, pp. 189-202, 2010.

[45] B. Anuncibay-Soto, D. Pérez-Rodríguez, M. Santos-Galdiano, E. Font, M. Regueiro-Purriños, and A. Fernández-López, "Postischemic salubrinal treatment results in a neuroprotective role in global cerebral ischemia," Journal of Neurochemistry, vol. 138, no. 2, pp. 295-306, 2016.

[46] X.-H. Cai, X.-C. Li, S.-W. Jin et al., "Endoplasmic reticulum stress plays critical role in brain damage after chronic intermittent hypoxia in growing rats," Experimental Neurology, vol. 257, pp. 148-156, 2014.

[47] Y. Zhu, P. Fenik, G. Zhan, B. Sanfillipo-Cohn, N. Naidoo, and S. C. Veasey, "Eif-2a protects brainstem motoneurons in a murine model of sleep apnea," Journal of Neuroscience, vol. 28, no. 9, pp. 2168-2178, 2008.

[48] V. Rubovitch, S. Barak, L. Rachmany, R. B. Goldstein, Y. Zilberstein, and C. G. Pick, "The neuroprotective effect of salubrinal in a mouse model of traumatic brain injury," NeuroMolecular Medicine, vol. 17, no. 1, pp. 58-70, 2015.

[49] A. F. Logsdon, B. P. Lucke-Wold, L. Nguyen et al., "Salubrinal reduces oxidative stress, neuroinflammation and impulsive-like behavior in a rodent model of traumatic brain injury," Brain Research, vol. 1643, pp. 140-151, 2016.

[50] M. A. Barreda-Manso, N. Yanguas-Casás, M. Nieto-Sampedro, and L. Romero-Ramírez, "Neuroprotection and blood-brain barrier restoration by salubrinal after a cortical stab injury," Journal of Cellular Physiology, vol. 232, no. 6, pp. 1501-1510, 2017.

[51] S. S. Ohri, M. Hetman, and S. R. Whittemore, "Restoring endoplasmic reticulum homeostasis improves functional recovery after spinal cord injury," Neurobiology of Disease, vol. 58, pp. 2937, 2013.

[52] L. Romero-Ramírez, M. Nieto-Sampedro, and M. A. BarredaManso, "All roads go to salubrinal: endoplasmic reticulum stress, neuroprotection and glial scar formation," Neural Regeneration Research, vol. 10, no. 12, pp. 1926-1927, 2015.
[53] M. Sakata, H. Yanamoto, N. Hashimoto et al., "Induction of infarct tolerance by platelet-derived growth factor against temporary focal ischemia," Brain Research, vol. 784, no. 1-2, pp. 250-255, 1998.

[54] J. Krupinski, R. Issa, T. Bujny et al., "A putative role for plateletderived growth factor in anglogenesis and neuroprotection after ischemic stroke in humans," Stroke, vol. 28, no. 3, pp. 564-573, 1997.

[55] H. C. Tseng and M. A. Dichter, "Platelet-derived growth factor-BB pretreatment attenuates excitotoxic death in cultured hippocampal neurons," Neurobiology of Disease, vol. 19, no. 1-2, pp. 77-83, 2005.

[56] L. Zheng, Y. Ishii, A. Tokunaga et al., "Neuroprotective effects of PDGF against oxidative stress and the signaling pathway involved," Journal of Neuroscience Research, vol. 88, no. 6, pp. 1273-1284, 2010.

[57] B. Obermeier, R. Daneman, and R. M. Ransohoff, "Development, maintenance and disruption of the blood-brain barrier," Nature Medicine, vol. 19, no. 12, pp. 1584-1596, 2013.

[58] S. Gyoneva and R. M. Ransohoff, "Inflammatory reaction after traumatic brain injury: therapeutic potential of targeting cellcell communication by chemokines," Trends in Pharmacological Sciences, vol. 36, no. 7, pp. 471-480, 2015.

[59] M. Hellström, M. Kalén, P. Lindahl, A. Abramsson, and C. Betsholtz, "Role of PDGF-B and PDGFR- $\beta$ in recruitment of vascular smooth muscle cells and pericytes during embryonic blood vessel formation in the mouse," Development, vol. 126, no. 14, pp. 3047-3055, 1999.

[60] N. Makihara, K. Arimura, T. Ago et al., "Involvement of platelet-derived growth factor receptor $\beta$ in fibrosis through extracellular matrix protein production after ischemic stroke," Experimental Neurology, vol. 264, pp. 127-134, 2015.

[61] G. A. Rosenberg, M. Kornfeld, E. Estrada, R. O. Kelley, L. A. Liotta, and W. G. Stetler-Stevenson, "TIMP-2 reduces proteolytic opening of blood-brain barrier by type IV collagenase," Brain Research, vol. 576, no. 2, pp. 203-207, 1992.

[62] M. Ueno, B. Wu, A. Nishiyama et al., "The expression of matrix metalloproteinase-13 is increased in vessels with blood-brain barrier impairment in a stroke-prone hypertensive model," Hypertension Research, vol. 32, no. 5, pp. 332-338, 2009.

[63] E. H. Wilson, W. Weninger, and C. A. Hunter, "Trafficking of immune cells in the central nervous system," Journal of Clinical Investigation, vol. 120, no. 5, pp. 1368-1379, 2010.

[64] B. Anuncibay-Soto, M. Santos-Galdiano, and A. FernándezLópez, "Neuroprotection by salubrinal treatment in global cerebral ischemia," Neural Regeneration Research, vol. 11, no. 11, pp. 1744-1745, 2016.

[65] X. Huang, Y. Chen, H. Zhang, Q. Ma, Y. Zhang, and H. Xu, "Salubrinal attenuates $\beta$-amyloid-induced neuronal death and microglial activation by inhibition of the NF- $\kappa$ B pathway," Neurobiology of Aging, vol. 33, no. 5, pp. 1007.e9-1007.e17, 2012.

[66] S. Nakajima, Y. Chi, K. Gao, K. Kono, and J. Yao, "eIF2 $\alpha-$ independent inhibition of TNF- $\alpha$-triggered NF- $\kappa$ B activation by salubrinal," Biological \& Pharmaceutical Bulletin, vol. 38, no. 9, pp. 1368-1374, 2015.

[67] H. Ceulemans and M. Bollen, "Functional diversity of protein phosphatase-1, a cellular economizer and reset button," Physiological Reviews, vol. 84, no. 1, pp. 1-39, 2004.

[68] C. Raposo and M. Schwartz, "Glial scar and immune cell involvement in tissue remodeling and repair following acute CNS injuries," Glia, vol. 62, no. 11, pp. 1895-1904, 2014. 
[69] R. A. Asher, D. A. Morgenstern, L. D. F. Moon, and J. W. Fawcett, "Chondroitin sulphate proteoglycans: inhibitory components of the glial scar," Progress in Brain Research, vol. 132, pp. 611-619, 2001.

[70] M. A. Barreda-Manso, N. Yanguas-Casás, M. Nieto-Sampedro, and L. Romero-Ramírez, "Salubrinal inhibits the expression of proteoglycans and favors neurite outgrowth from cortical neurons in vitro," Experimental Cell Research, vol. 335, no. 1, pp. 82-90, 2015.

[71] M. Cnop, L. Ladriere, P. Hekerman et al., "Selective inhibition of eukaryotic translation initiation factor $2 \alpha$ dephosphorylation potentiates fatty acid-induced endoplasmic reticulum stress and causes pancreatic $\beta$-cell dysfunction and apoptosis," Journal of Biological Chemistry, vol. 282, no. 6, pp. 3989-3997, 2007.

[72] B. Gao, X.-Y. Zhang, R. Han et al., "The endoplasmic reticulum stress inhibitor salubrinal inhibits the activation of autophagy and neuroprotection induced by brain ischemic preconditioning," Acta Pharmacologica Sinica, vol. 34, no. 5, pp. 657-666, 2013.

[73] S. W. Way and B. Popko, "Harnessing the integrated stress response for the treatment of multiple sclerosis," The Lancet Neurology, vol. 15, no. 4, pp. 434-443, 2016.

[74] B. Holmes, R. N. Brogden, R. C. Heel, T. M. Speight, and G. S. Avery, "Guanabenz: a review of its pharmacodynamic properties and therapeutic efficacy in hypertension," Drugs, vol. 26, no. 3, pp. 212-229, 1983.

[75] S. W. Way, J. R. Podojil, B. L. Clayton et al., "Pharmaceutical integrated stress response enhancement protects oligodendrocytes and provides a potential multiple sclerosis therapeutic," Nature Communications, vol. 6, article 6532, 2015.

[76] S. S. Ohri, A. Mullins, M. Hetman, and S. R. Whittemore, "Inhibition of GADD34, the stress-inducible regulatory subunit of the endoplasmic reticulum stress response, does not enhance functional recovery after spinal cord injury," PLoS ONE, vol. 9, no. 11, Article ID e109703, 2014.

[77] P. K. Dash, M. J. Hylin, K. N. Hood et al., "Inhibition of eukaryotic initiation factor 2 alpha phosphatase reduces tissue damage and improves learning and memory after experimental traumatic brain injury," Journal of Neurotrauma, vol. 32, no. 20, pp. 1608-1620, 2015.

[78] A. H. Hall, S. C. Smolinske, K. W. Kulig, and B. H. Rumack, "Guanabenz overdose," Annals of Internal Medicine, vol. 102, no. 6, pp. 787-788, 1985. 

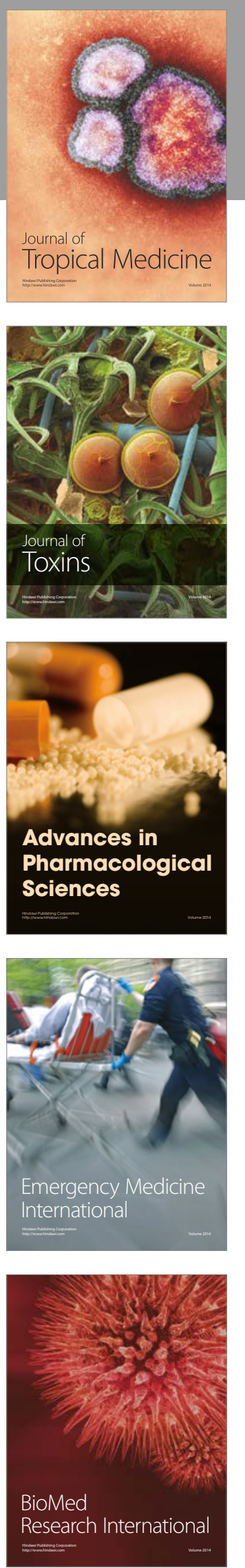
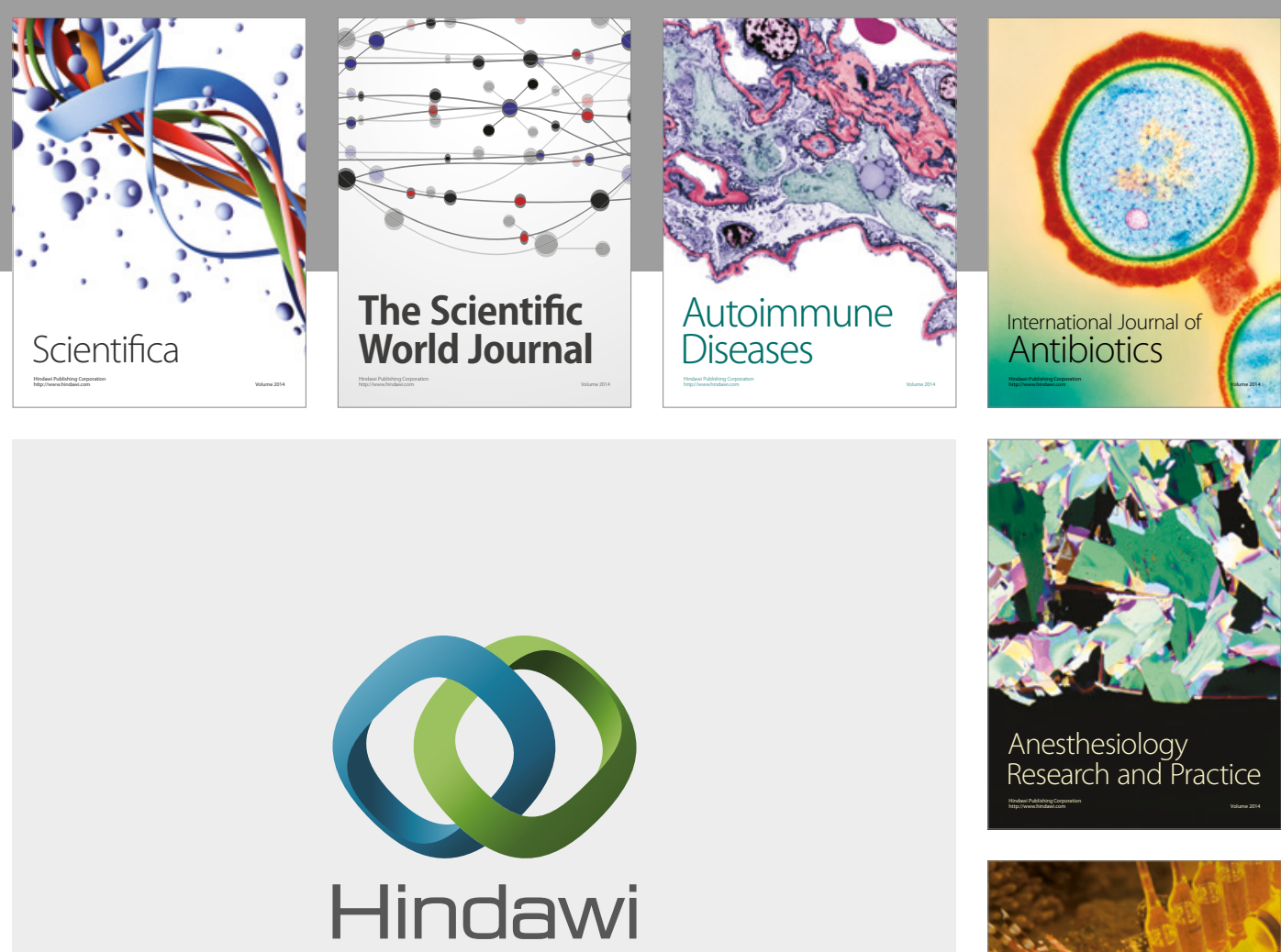

Submit your manuscripts at

https://www.hindawi.com
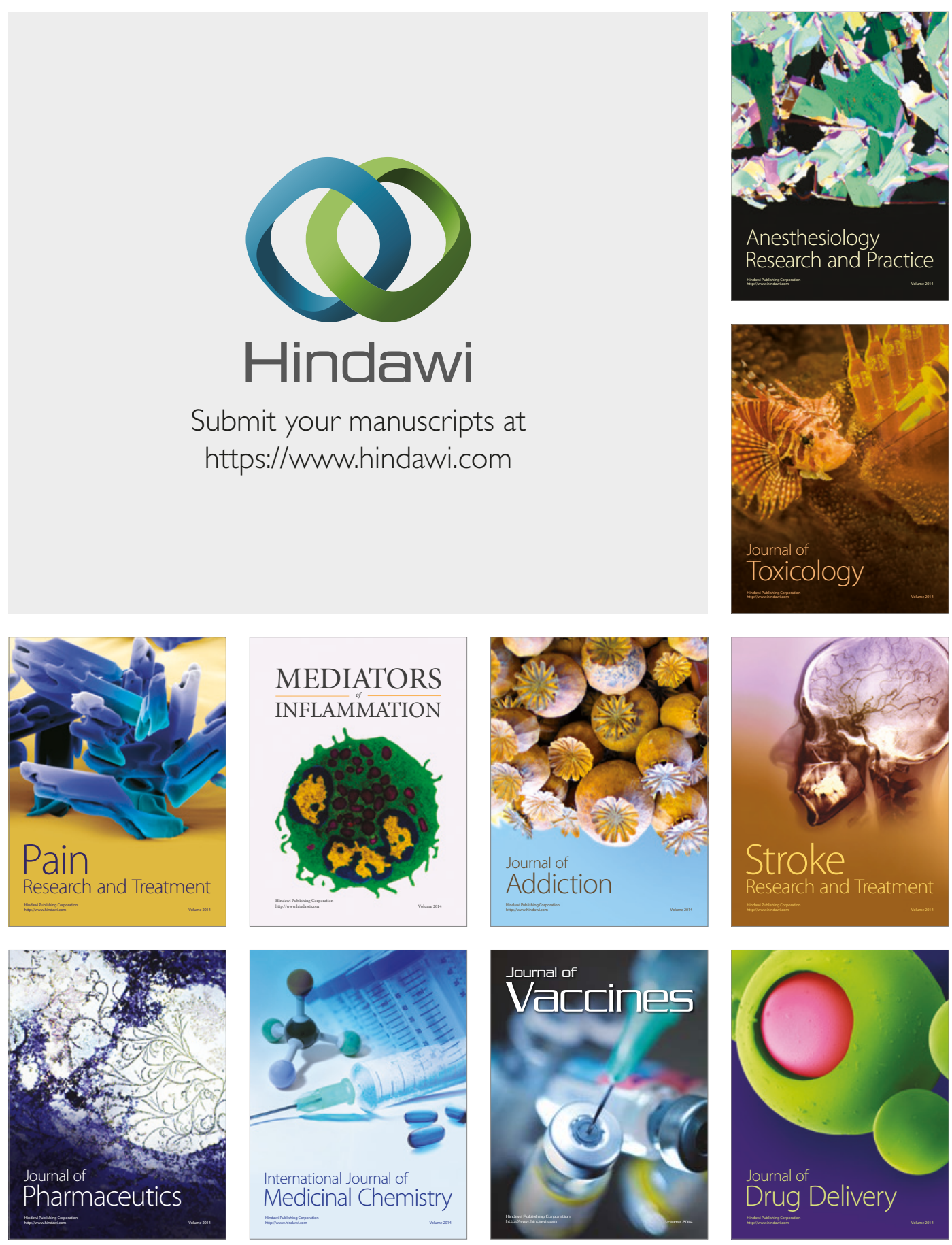